\title{
Evolution: Improving the Understanding of Undergraduate Biology Students with an Active Pedagogical Approach
}

\author{
Sam Buckberry • Karen Burke da Silva
}

Published online: 29 April 2012

(C) Springer Science+Business Media, LLC 2012

\begin{abstract}
Students in a large introductory biology course at Flinders University, South Australia, were quizzed on misconceptions relating to evolution and their acceptance of evolutionary theory before and after completing the course. By providing students with a course featuring a multifaceted approach to learning about evolution, students improved their understanding and decreased their overall misconceptions. A variety of instructional methods and assessment tools were utilized in the course, and it employed an active and historically rich pedagogical approach. Although student learning and understanding of evolutionary theory improved throughout the course, it did not alter the beliefs of students who commented both before and after the course that religious theories provided adequate explanation for the diversity of life. Interestingly, students who maintained this belief scored more poorly on the final examination than students who considered evolution as the best explanation for the diversity of life.
\end{abstract}

Keywords Evolution · Education · Undergraduate .

Pedagogy $\cdot$ Creationism

\section{Introduction}

The theory of evolution unites all of biology. This idea is well summarized in Dobzhansky's (1973) aptly titled paper, "Nothing in Biology Makes Sense Except in the Light of

S. Buckberry $\cdot$ K. Burke da Silva $(\bowtie)$

School of Biological Sciences, Flinders University,

GPO Box 2100, Adelaide 5001, Australia

e-mail: karen.burkedasilva@flinders.edu.au

S. Buckberry

e-mail: sam.buckberry@adelaide.edu.au
Evolution." Given the unifying and explanatory power of this theory, it would be reasonable to expect that its fundamental principles and concepts would be widely and generally understood, especially by those studying the life sciences. However, as a large and continually growing body of research suggests, this is not the case (Chinsamy and Plaganyi 2008; Pazza et al. 2010; Cunningham and Wescott 2009; Abraham et al. 2009; Hokayem and BouJaoude 2008; Nehm and Reilly 2007). There is usually a high degree of acceptance regarding scientific explanations in discussions of life situations and nature, but not in considering how the natural world we know came to be through evolutionary processes (Hokayem and BouJaoude 2008).

Why, then, do so many people lack an understanding of the principles of evolution and natural selection? The first logical explanation would assume that these principles are difficult to understand. However, the basic concepts of evolution and natural selection are relatively simple, and as Muller (1959) describes in his classic paper "One hundred years without Darwinism are enough," children can easily grasp these concepts at a very young age, and once understood, they should be applied as new cases are encountered. Muller's (1959) arguments on evolution education are as strong and relevant today as when they were published more than 50 years ago.

If the process of evolution is relatively simple, why is it not widely accepted and understood? One apparent reason is that an opposition, or a competing idea, exists that casts doubt in the minds of some individuals, causing skepticism about the theory of evolution. Naturally, science encourages skepticism, and a skeptical nature in science leads to thorough questioning, testing and review, which allow theories to develop. One of the widespread oppositions to evolutionary theory arises from its contravening idea of divine creation. The religious opposition to the vast explanatory power of evolution has no doubt had a profound effect on the teaching, understanding 
and acceptance of evolution. Campaigns have been and continue to be fought to ban the teaching of evolution in schools (Berkman and Plutzer 2011). If these campaigns are successful, this leaves the next generation of scientists, teachers, politicians and community leaders, along with the broader public, with a poor understanding of a theory of life that holds broad-spanning implications. Some of these campaigners have fought to give opposing ideas taught in schools equal weight to that of evolution, even though these ideas lack convincing evidence (Berkman and Plutzer 2011). Opponents to the teaching of evolution essentially claim that all the evidence for biological evolution is comparable to the evidence of creation theories (Berkman and Plutzer 2011).

The theory of evolution is often referred to in the pejorative sense, in that it is just a theory and comparable to other theories, such as the creation theory (Pazza et al. 2010; Hokayem and BouJaoude 2008; Bishop and Anderson 1990; Alters and Nelson 2002). It is easy to tangle with semantics here, and as Dawkins (2009) points out in his discussion "What is a theory? What is a fact?" two (or more) quite different meanings for the word theory are widely used. Scientists generally use the word theory to describe a scheme or system of ideas or statements that account for a massive group of facts or phenomena (Dawkins 2009). The other meaning of the word theory in common use describes ideas, speculations and conjecture about the nature of an entity (Dawkins 2009). Both meanings of the word are used when discussing evolution, but those who favor creation theory often use the latter (Dawkins 2009). The use of this particular meaning of the word theory clearly demonstrates a lack of understanding of the scientific method, the nature of scientific theory, and how evolution is explained by the theories regarding how it is driven (Dawkins 2009).

However, even those individuals who accept the validity of evolutionary theory do not always understand how its mechanisms work (Cunningham and Wescott 2009). Because of these misunderstandings, many misconceptions have become associated with evolution. These misconceptions may be rooted in a partially understood or misunderstood component of evolutionary theory. If these misconceptions fit with an existing understanding of the world, there can be a resistance to conceptual change (Sinatra et al. 2008). Misconceptions about the nature of evolution can also lead to the apparent acceptance of evolution without understanding the essence and explanatory power of the theory.

Our study was conducted in Australia, where very few previous studies on the acceptance and misconceptions related to evolution have been conducted. Brumby's (1984) study, which examined the misconceptions surrounding natural selection among Australian medical biology students, revealed that questions about natural selection were answered correctly more often by students with a high school biology education. Additionally, the results indicated that a majority of students consider evolutionary changes occur out of need (a Lamarckian view) and that they do not merely exhibit simple errors of knowledge, but their "entire pattern of reasoning is faulty," which is a result of deep-seated misconceptions (Brumby 1984). Short (1994) issued an evolution questionnaire to Australian medical students before and after they took a course in evolution. In this study, the majority of students did not accept evolutionary theory before taking the course, and this non-acceptance correlated significantly with no high school biology education, religious belief and frequency of worship (Short 1994). Short's (1994) analysis indicated no statistically significant changes between the answers to any of the questions after the course in evolution was completed. In fact, Short (1994) suggests that the emotional and irrational beliefs about life are perhaps beyond the reach of scientific logic. A study by Kelley (1999) showed that ideas pertaining to the theory of evolution elicited a mixed reaction in Australian society, but with the balance of opinion favoring a Darwinian explanation. Kelley indicated that religion and education are the key social differences in the acceptance of evolution and suggests that acceptance of evolution will gradually increase in Australia "as older, less educated, more devout cohorts are replaced by younger, better educated, less religious ones" (Kelley 1999).

In contrast to Australia, many studies concerning the acceptance and misconceptions surrounding evolution have been conducted in the United States, and several of these focus on students in higher education. Bishop and Anderson (1990) issued pre- and post-tests to undergraduate biology students, where they found that previous biology education had no influence on pre- or post-test performance and that the students' acceptance of evolution was only slightly affected by instruction. Jensen and Finley (1996) also issued pre- and postcourse tests, but compared the results between groups of differing instruction methods. Their results indicate that a historically rich and problem-solving method of instruction significantly outperformed the more traditional textbook pedagogical approach (Jensen and Finley 1996). Nehm and Reilly's (2007) study also compared pedagogical approaches with pre- and post-course tests, revealing that an activelearning style of instruction outperformed a more traditional approach, but both groups still demonstrated inadequate levels of evolutionary understanding. Again, Sinclair et al. (1997) employed a pre- and post course test, but focused on the relationship between religion and the acceptance of evolutionary theory among zoology students. Their study showed that students' religious beliefs could interfere with an ability to view scientific evidence, especially when the evidence being presented counters their religious teachings (Sinclair et al. 1997). Cunningham and Wescott (2009) evaluated the evolutionary understanding of biological anthropology students with a pre-course questionnaire, with their results suggesting that student understanding of evolution is limited even among 
those who accept the validity of evolutionary theory. Their study demonstrates that even acceptance of evolutionary theory does not imply understanding and that misconceptions must be identified if instructors are to assist students in undergoing conceptual change (Cunningham and Wescott 2009). The above-mentioned studies suggest that most presently used traditional methods of teaching evolutionary biology are relatively ineffective at dispelling misconceptions and increasing acceptance of evolution (Kelley 1999; Jensen and Finley 1996; Short 1994; Sinclair et al. 1997; Cunningham and Wescott 2009; Bishop and Anderson 1990).

The theory of evolution is well established and accepted widely by scientists (Delgado 2006). Through rigorous scientific research, when something is established beyond the point of reasonable doubt, it is the responsibility of the scientific community to report to and educate the wider community. As societies around the globe become more reliant on information of a scientific nature, it is the duty of scientists and educators to do their best to advocate the facts to advance accurate understanding. Religious beliefs may be the source of much opposition to evolutionary theory, but a lack of education and, in response, a poor understanding of evolutionary theory appears to maintain the low level of understanding and acceptance of evolution (Kelley 1999).

It is reasonable to suggest that individuals who choose to be educated at the university level in the sciences have a basic understanding of scientific principles, methods and widely accepted theories - or are at least inclined to scientific rationale. Conversely, several studies indicate that nonacceptance and misconceptions surrounding evolution are highly prevalent among those studying the sciences in higher education (Alters and Nelson 2002; Brumby 1984; Bishop and Anderson 1990; Cunningham and Wescott 2009; Nehm and Reilly 2007). This growing realization of the widespread non-acceptance and misconceptions associated with evolutionary biology has prompted educators and researchers to examine the pedagogical approaches applied to teaching of evolution in higher education.

Our study was designed to assess the acceptance and misconceptions regarding evolution among first-year university students enrolled in their second semester course, Evolution of Biological Diversity. This course includes a variety of instructional methods and assessment tools and generally employs an active and historically rich pedagogical approach (Nehm and Reilly 2007; Jensen and Finley 1996). The course was designed to emphasize evolution using biological diversity as examples rather than the more typical first-year approach, which is to teach biological diversity using an evolutionary approach. The focus of the course was to facilitate a better understanding of evolutionary theory in first-year science students. Our aim was to introduce evolution in the very early stage of the degree program rather than at the end, where it is typically found in most university programs. By introducing the course early, students could then use this knowledge in their future courses, and non-biology majors who only study first-year biology would be able to move forward with a comprehensive understanding of evolution. The aim of our study was to evaluate whether the course Evolution of Biological Diversity was effective at challenging misconceptions and increasing the acceptance of evolutionary theory. We conducted a pre- and post-test to gauge the level of acceptance and misconceptions surrounding evolution among the students enrolled in the course. Additionally, by gauging the level of acceptance of evolution, we hoped to establish if this influenced the students' level of understanding of evolution and their overall success in the course.

\section{Methods}

The course Evolution of Biological Diversity at Flinders University of South Australia is characterized by a multifaceted approach to learning about evolution, using evolution as a unifying theme. The content is historically rich and poses fundamental questions about the diversity of life, and how evolutionary processes and theory explain diversity. This firstyear course is delivered over 13 weeks and is comprised of pre-lectures, lectures, "lectorials," practical laboratory sessions and peer-assisted study sessions (PASS). Assessment components include online weekly quizzes, practical reports, assignments, and mid-semester and final exams. Pre-lectures introduce students to terminology that they will need to understand the following lectures of the week, a brief outline of the concepts and an opportunity for students to gain confidence in their abilities in understanding the material. Prelectures are designed specifically for students without a high school biology background, but can be attended by anyone (Burke da Silva and Hunter 2009). Two lectures are given each week by academics with expertise in the area of evolution presented. The lectures include embedded questions or problem-solving components and the use of audience response instruments such as clickers or votapedia. The last lecture of each week is called a "lectorial," which is presented as an interactive session where students are required to apply or examine the material covered in the current week's lectures as it applies to real-world problems or issues. Practical sessions are closely aligned with lecture material and are highly interactive and investigative in nature. Each three-hour session provides students with the opportunity to interact with theory through practical example and allows students to observe biological diversity first hand. PASS are facilitated by highachieving students who possess a strong understanding of the course material and can communicate their understanding confidently and effectively. PASS do not involve the introduction of new material and have no associated assessment. During PASS, facilitators employ a diverse array of learning 
techniques to guide first-year students toward discovering answers themselves through the application of knowledge (Burke da Silva and Auburn 2009).

Before the introduction of the current course structure, the previous first-year course included a more traditional pedagogical approach of three standard lectures per week and one practical session per fortnight. The previous course material emphasized cladistics and phylogenetics, and performing well was essentially measured by the ability to classify organisms based on characteristics. Therefore, this previous course structure provided students with knowledge about organisms rather than knowledge about evolution.

At the start of the 2009 course, we distributed a true/false quiz among the students in place of their first weekly quiz assessment (Table 1). The students were told that if they completed the questionnaire, they would receive full marks for that component; hence, there was incentive to complete the questionnaire, but there was no penalty for incorrect answers. After the completion of the course, students were reissued the identical questionnaire under the same conditions as at the start of the course.

Students were asked to respond "true" or "false" to a series of statements regarding specific questions surrounding misconceptions and the acceptance of evolution (Table 1). The final two statements related to the overall acceptance and validity of evolutionary theory, and students were able to provide comments concerning alternative explanations and/or justification of their viewpoints. Students were also asked whether they had completed high school biology.

Pre- and post-course questionnaires were divided into three different groups: pre-teaching $(n=351)$, post-teaching $(n=$ $217)$, and a paired pre- and post group $(n=180)$. The questionnaire was scored out of 22 questions and the comments relating to the final two questions were analyzed separately. One of the questions (Q21, Table 1) was identified as the best measure of the overall acceptance of evolutionary theory. The results of this question were then used to establish whether acceptance of evolutionary theory correlated with final examination score and overall course grade.

\section{Results}

Pre-course Questionnaire $(n=351)$

Of the 351 students who completed the pre-course questionnaire, $63 \%$ had completed high school biology and $37 \%$ had

Table 1 Paired data results $(n=180)$ for each question from pre- and post-teaching evolution quiz given to students of "Evolution of Biological Diversity," Flinders University, South Australia

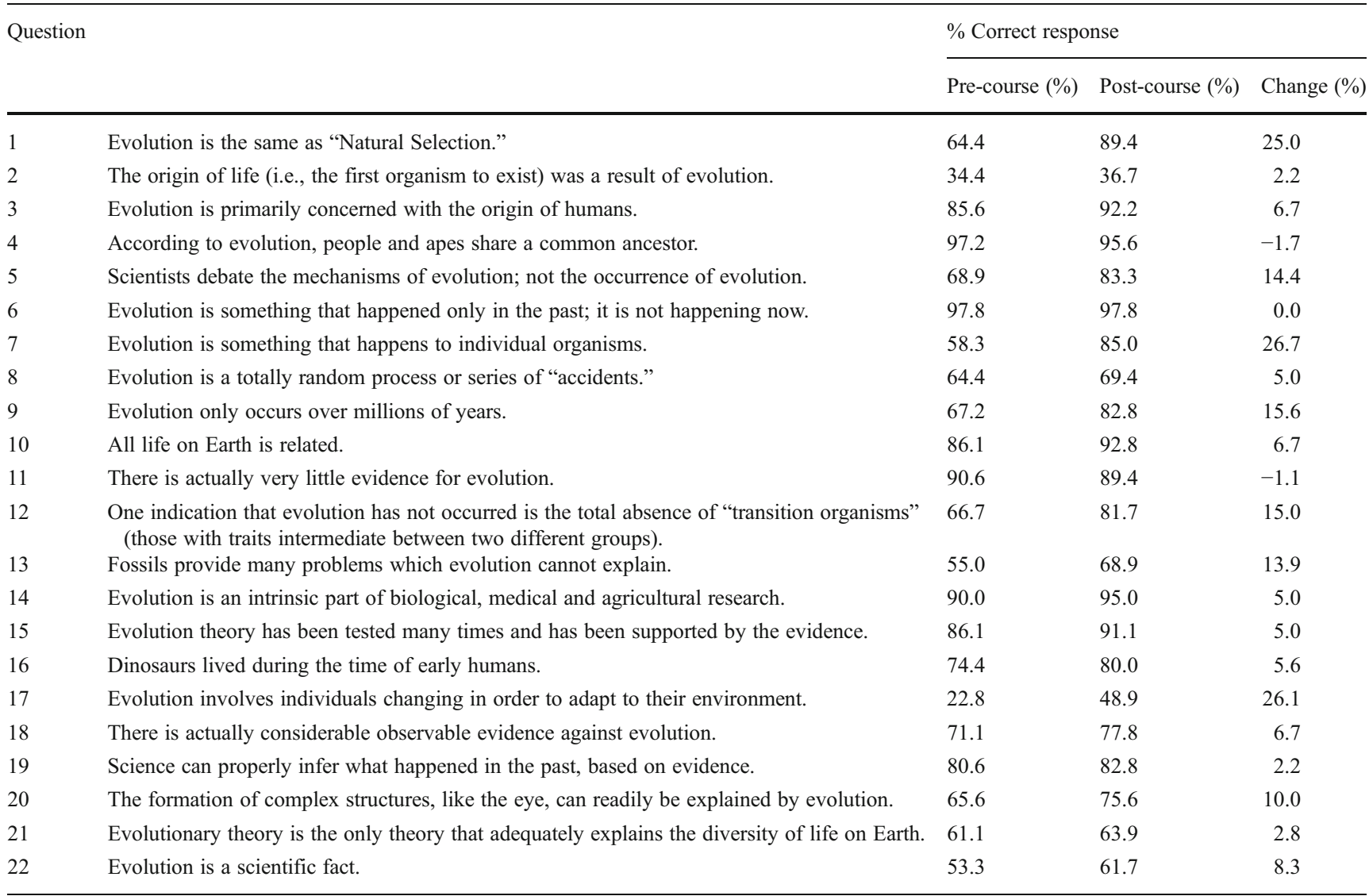


not. A Wilcoxon signed ranks test indicated a significant difference $(p=0.007)$ between students who had completed high school biology (mean 15.91) and those who had not (mean 15.36), although the magnitude of this difference was low.

Paired Data for Pre- and Post-course $(n=180)$

The results of questions from students who completed both the pre- and post-course questionnaire were analyzed by applying a paired samples $t$-test. A highly significant $(p=<0.0001)$ improvement from a mean pre-teaching score of $71 \%$ to a mean post-teaching score of $81 \%$ was found.

To further assess whether a background in high school biology affected student improvement, this paired group was split into students who had completed high school biology $(n=116)$ and those who had not $(n=64)$. Both groups showed significant increases $(p<0.001$, Wilcoxon signed ranks test) in test scores. The group that had completed high school biology showed an increase of $9 \%$ (from $72 \%$ to $81 \%$ ), and the group that had not completed high school biology showed an increase of $11 \%$ (from $70 \%$ to $81 \%$ ) overall. The data on the final scores of those two groups were compared by applying the Mann-Whitney $U$-test and found not to be significantly different $(p=0.187)$ between the improvement of those students who had completed year 12 biology and those who had not. For paired results for individual questions, refer to Table 1.

Post-course Questionnaire $(n=217)$

The results for questions 21 and 22 and the comments relating to the answers provided were grouped accordingly.

When commenting on the statement "evolutionary theory is the only theory that adequately explains the diversity of life on Earth," $20 \%$ of students who completed the post-course questionnaire made comments suggesting that religious theories provided adequate explanation for the diversity of life on Earth.

Sixty-three percent of students who completed the postcourse questionnaire responded "true" to the statement "evolution is a scientific fact." Of these students, 38\% responded "false" to the statement "evolutionary theory is the only theory that adequately explains the diversity of life on Earth."

The quiz results were then split into two groups: those who answered true $(n=139)$ to "Evolutionary theory is the only theory that adequately explains the diversity of life on Earth" (Q21) and those who answered false $(n=78)$. To determine whether there was a significant difference in the scores between these two groups (minus the score for Q21), an unpaired $t$-test was applied to the datasets. The results indicate that students who responded "true" to the statement achieved significantly ( $p=0.002$ ) higher marks on the quiz. The results for the final examination were then assessed regarding the acceptance of evolution. This showed that students who accepted evolution on average scored better ( $67.52 \%$ vs. $62.50 \%, p=0.04)$ on the final examination of 100 multiple-choice questions. Students' final results for the overall course were tested for significant differences, again indicating that students who accepted evolution marginally outperformed $(p=0.04)$ students who did not.

\section{Discussion}

If our course, Evolution of Biological Diversity, was effective at challenging misconceptions and increasing the acceptance of evolutionary theory, we would expect to see a significant increase in the number of correct answers on our quiz after students complete the course. Our results do indicate a significant increase. Previous studies indicate that an active, historically rich learning style of instruction such as the one we have implemented would produce such results (Nehm and Reilly 2007; Jensen and Finley 1996). The active learning group in Nehm and Reilly's (2007) study employed evolution as a common thread through all units taught throughout the semester. They abandoned an exclusively lecture-based pedagogy and tests that rewarded factual recall (Nehm and Reilly 2007). Additionally, Nehm and Reilly (2007) achieved success by including discussions on the nature of science, problemsolving, group responses to questions and small group discussions. Our course is comparable to Nehm and Reilly's (2007) active approach in that ours also weaves evolution as a common thread through all the material presented. Our lecture approach is interactive, requiring student involvement, and course components such as PASS require that real-life problems be solved by the application of evolutionary concepts and theory. Additionally, the examination and quiz assessments focused primarily on applying evolutionary concepts rather than recalling individual facts. Our course also draws parallels with Jensen and Finley's (1996) study, in that our course is historically rich. For example, Evolution of Biological Diversity covers the history of thought before and after the publication of Darwin's theory, the fossil evidence for past extinctions, life history strategies, examples of co-evolution and the presentation of historically classic experiments that have provided fine examples of evolution. A historically rich and problem-solving-based curriculum in Jensen and Finley's (1996) study significantly outperformed the more traditional lecture pedagogy, further giving support to the effectiveness of our curriculum structure in providing students with a better understanding of the material presented.

The initial significant difference between those who had completed high school biology and those who had not suggests that students who received previous instruction 
on the principles of evolution and natural selection may be more familiar with the types of questions/statements posed in our questionnaire (Abraham et al. 2009). The high school biology curriculum for South Australia does indicate that students are exposed to the principles of evolution, so this could be a possible influencing factor in this significant difference. Brumby's (1984) Australian study also yielded similar results, suggesting a high school background in biology positively influences students' correct understanding of evolution. But these results are in contrast to Bishop and Anderson's (1990) study in the United States, where students who had taken previous biology courses showed little understanding of evolution. Although we are cautious in making this comparison as the students who completed high school biology in our study did perform significantly better, the magnitude of difference was low. Additionally, we cannot assume that a student who did not complete high school biology has not been otherwise exposed to the principles of evolution.

As our results indicate, students who had or had not completed high school biology improved their questionnaire scores significantly. Although there was no significant difference between the two groups post-course, the group who had not completed high school biology came from a lower baseline and thus showed greater improvement than those students who had completed high school biology. Additionally, as there was no difference between the two groups post-course, it would be reasonable to suggest that both groups have a comparable acceptance of evolutionary theory and harbor the same levels of misconceptions after completing the course. This indicates that all students can achieve similar success and understanding on the topic regardless of their background in biology.

The greatest increase in correct responses from pre- to post-course occurred with questions that related to evolution involving changes within an individual, which can be seen as Lamarckian and/or teleological ideas of evolution. It is well established that these types of ideas about evolution are often the basis of many misconceptions (Alters and Nelson 2002; Bishop and Anderson 1990; Brumby 1984; Jensen and Finley 1996; Cunningham and Wescott 2009). For example, before taking our course, 58\% (Q7, Table 1) of students answered "false" to the statement "evolution is something that happens to individual organisms" (Q7, Table 1). Eighty-five percent of students answered "false" to this question post-course, indicating a $27 \%$ increase in correct answers. A similar increase in correct results was also observed for the answers to the statement "evolution involves individuals changing in order to adapt to their environment" (Q17, Table 1). If many misconceptions are rooted in this school of thought, then our course has been a success in that a large proportion of students who harbor an individualcentered concept of evolution now apply a more correct, population-based understanding.
When analyzing the results of our post-course quiz, we divided the students into two groups based on their true/false response to "evolutionary theory is the only theory that adequately explains the diversity of life on Earth." The answers to this statement are probably our most accurate measure of whether students accept the validity of evolutionary theory. This is supported by Cunningham and Wescott, (2009), who found that similar statements in their study were also effective at measuring acceptance. Examining the post-course quiz results, final examination results, and the final results for the overall topic, we found that the group that responded "true" to "evolutionary theory is the only theory that adequately explains the diversity of life on Earth" significantly outperformed those who responded "false." This suggests that acceptance of the validity of evolutionary theory is associated with a greater, more in-depth understanding in our group. If this is the case, our results contradict those of previous U.S. studies that suggest that the acceptance or rejection of the validity of evolutionary theory does not impact students' ability to learn and understand the processes involved in evolution (Bishop and Anderson 1990; Cunningham and Wescott 2009).

Although the acceptance of evolution may affect a student's overall success in our course on evolution, our course appeared to have little effect in changing the level of acceptance of evolution. Our results indicate that pre-course (61\%) and post-course $(64 \%)$ of students accept that evolution adequately explains life's diversity on Earth. This small magnitude of change was also experienced by Chinsamy and Plaganyi (2008) when analyzing their results to a similar question, subsequently leading the authors to suggest that their course on evolution had a negligible effect in shifting students' views on this concept. When students commented on this statement in the post-course quiz, they generally suggested that religious theories were adequate in explaining life's diversity. Typical responses suggested that "Genesis theory," "intelligent design" and "creationism" were adequate theories. Overall, the comments from this question post-course suggest that $20 \%$ of students felt that religious theories are adequate in explaining biological diversity. This finding is also reflected in the results of previous studies, suggesting that students who rejected or were uncertain about the validity of evolution found the evidence for evolution comparable to that provided in religious explanations (Hokayem and BouJaoude 2008; Cunningham and Wescott 2009).

Students were also asked if they thought there is considerable, observable evidence against evolution (Q18, Table 1). As religious-based evidence appears to be the most prominently stated form of evidence other than that provided by scientific research, it would be reasonable to suggest those who thought there is observable evidence against evolution would have religious-based evidence in mind. A strong 
majority ( $71 \%$ pre-course and $78 \%$ post-course) of students in our study disagreed with this statement, leaving a surprisingly large minority of students who believe that there is considerable observable evidence against evolution. This small change was unexpected, as a large amount of evidence for evolution is provided throughout the course, but it suggests to us that perhaps in the future, the apparent evidence against evolution must be dealt with more adequately. However, this could possibly be partly accounted for by those $20 \%$ of students who felt that religious theories provide an adequate explanation of biological diversity, and if their religious convictions are strong, countering this evidence may simply fall on deaf ears. Cunningham and Wescott (2009) had similar results to a comparable question, with $68 \%$ of students disagreeing that there is considerable evidence against evolution. They found that agreement or disagreement with this statement substantially affected the answers to other statements in the questionnaire (Cunningham and Wescott 2009). This gives further support to the idea that non-acceptance of evolutionary theory or favoring alternative evidence can affect a sound understanding of evolution.

The final true/false statement in our quiz prompted a response to the statement "evolution is a scientific fact," and space was provided for comment if the response was "false." When answering "false" to "evolution is a scientific fact," $12 \%$ of students made comments suggesting that it was a theory and not a fact; $13 \%$ of students commented, suggesting that it is not a fact, but a theory with much supporting evidence; and $12 \%$ of students commented, suggesting that there is not enough evidence and evolution is only a theory. A concern remains regarding those students who suggested that there is not enough evidence, but as discussed above, this belief may be due to some form of religious persuasion. The magnitude of change from preto post course on this quiz item was relatively low, but confusion in answering this question may arise from the semantics involved with the word fact. It is understandable that some confusion could occur when answering this question, as the general philosophy of science tells us that we can't prove anything, and that all we can do is fail to disprove things while pointing out how hard we tried (Dawkins 2009). The first "lectorial" session of the semester discusses evolution as fact and theory, and how the fact of evolution is explained by the theory of evolution. Other scientific theories are used as analogies in this session, i.e., how the theory of gravity explains the fact of gravity.

The research presented here was conducted in Australia, where societal values and religious convictions differ from those in the United States, where much of the previous research in this field has been conducted. Around $50 \%$ of Australians almost never attend religious services, and just over $50 \%$ would refer to themselves as a religious person (World Values Survey 2005/2006). This is in contrast to the United States, where only around $25 \%$ of people claim to almost never attend religious services and where over $72 \%$ would refer to themselves as a religious person (World Values Survey 2005/2006). Kelley's (1999) study of Australian society indicates that churchgoers and those with strong religious beliefs are much more likely to reject evolution, and Miller et al. (2006) indicates that the level of acceptance of evolution in the United States is related to the belief in a personal god and widespread religious fundamentalism. Based on the aforementioned information, it would be reasonable to suggest that the differences in the level of acceptance of some evolutionary concepts could be due to these societal differences with respect to religion.

\section{References}

Abraham J, Meir E, Perry J, Herron J, Maruca S, Stal D. Addressing undergraduate student misconceptions about natural selection with an interactive simulated laboratory. Evol Educ Outreach. 2009;2(3):393-404.

Alters BJ, Nelson CE. Perspective: teaching evolution in higher education. Evolution. 2002;56(10):1891-901.

Berkman MB, Plutzer E. Defeating creationism in the courtroom, but not in the classroom. Science. 2011;331(6016):404-5.

Bishop BA, Anderson CW. Student conceptions of natural selection and its role in evolution. J Res Sci Teach. 1990;27(5):415-27.

Brumby MN. Misconceptions about the concept of natural selection by medical biology students. Sci Educ. 1984;68(4):493503.

Burke da Silva K, Auburn Z. The development of a structured "Peer Assisted Study Program" with required attendance. First Year in Higher Education Conference; Queensland University of Technology; 2009.

Burke da Silva K, Hunter N. The use of pre-lectures in a university biology course - eliminating the need for prerequisites. Biosci Educ. 2009;14:7.

Chinsamy A, Plaganyi E. Accepting evolution. Evolution. 2008;62 (1):248-54. doi:10.1111/j.1558-5646.2007.00276.x.

Cunningham D, Wescott D. Still more "fancy" and "myth" than "fact" in students' conceptions of evolution. Evol Educ Outreach. 2009;2(3):505-17.

Dawkins R. The greatest show on Earth: the evidence for evolution. 1st ed. London: Bantam Press; 2009.

Delgado C. Finding the evolution in medicine. NIH Record. 2006; LVIII, 15(15).

Dobzhansky T. Nothing in biology makes sense except in the light of evolution. Am Biol Teach. 1973;35(3):125-9.

Hokayem H, BouJaoude S. College students' perceptions of the theory of evolution. J Res Sci Teach. 2008;45(4):395-419.

Jensen MS, Finley FN. Changes in students' understanding of evolution resulting from different curricular and instructional strategies. J Res Sci Teach. 1996;33(8):879-900.

Kelley J. Australians' views about the theory of evolution. Aust Soc Monit. 1999;2(5):114-9.

Miller JD, Scott EC, Okamoto S. Public acceptance of evolution. Science. 2006;313(5788):765-6. doi:10.1126/science.1126746. 
Muller HJ. One hundred years without Darwin are enough. Sch Sci Math. 1959;59:304-5.

Nehm RH, Reilly L. Biology majors' knowledge and misconceptions of natural selection. Bioscience. 2007;57(3):263-72.

Pazza R, Penteado P, Kavalco K. Misconceptions about evolution in Brazilian freshmen students. Evol Educ Outreach. 2010;3(1):10713.

Short RV. Darwin, have I failed you? Lancet. 1994;343(8896):528-9.
Sinatra G, Brem S, Evans E. Changing minds? Implications of conceptual change for teaching and learning about biological evolution. Evol Educ Outreach. 2008;1(2):189-95.

Sinclair A, Pendarvis MP, Baldwin B. The relationship between college zoology students' beliefs about evolutionary theory and religion. J Res Dev Educ. 1997;30(2):118-25.

World Values Survey. 2005/2006. www.worldvaluessurvey.org. Accessed 25/01/10. 